\title{
Safety in Coal Mines
}

$\mathrm{O}^{\mathrm{N}}$ December 14, 1935, a Royal Commission under the chairmanship of Lord Rockley was appointed to inquire into what steps could be taken to improve the health and safety of workers in coal mines in Great Britain, having regard to the many changes that have taken place in organization, equipment and experience gained since the Coal Mines Regulation Act of 1911. The Commission held fifty-two public meetings, and after hearing evidence from the principal interests concerned, as well as visiting a number of mines, presented its report in December last*. The Government has announced that it has accepted the report as the basis for new legislation. The report itself extends to about 250,000 words and, in addition to a volume of appendixes, 1,500 pages of evidence involving nearly 37,000 questions and answers have been published.

Though lengthy and containing many details the report of the Commission is in general unanimous ; the few reservations do not to any material extent affect its general tone. It is divided into twelve chapters each of which deals thoroughly with a phase of mining legislation or practice. The Commissioners have not examined exhaus. tively the details of the existing acts and regulations which form the present safety code, but instead have endeavoured to give the industry a new start by appealing to its sense of co-operation. They have attempted to frame a scheme for promoting a higher standard of safety which shall be positive or constructive rather than merely prohibitive or restrictive. The report is a considerate and reasonable document which in many respects differs fundamentally from the reports of the Royal Commissions on which the 1887 and 1911 Coal Mine Acts were based. These relied largely on compulsory compliance with rigid rules and regulations and tended to place the technical officers of the Department in the invidious position of being regarded by the industry as detectives instead of technical advisers.

If the suggestion of the Commission is to have any effect in reducing the accident rate in mines, a change of attitude to each other by all the partners in the industry, namely the administration, now the Mines Department of the Board of Trade, the coal owners, the colliery officials and the work people is essential. The point is emphasized that the problem of safety in mines, if substantial improvement is to be secured, must be attacked simultaneously from all sides by adequate

* Royal Commission on Safety in Coal Mines Report. (Cmđ. 5890.) Pp. Xxxil +520. (London: H.M. Stationery Office, 1938.) 78. 6d. net. strengthening of the administration, the setting of a higher standard of enforcement or observance of regulations, an improvement in the material conditions under which work is carried out, and the co-operation of all parties. This will have the effect of imposing heavy duties on the shoulders of the administration and inspectorate, and heavy obligations on the owners and managing officials.

The majority of mine owners, engineers and workmen do everything that is humanly possible to encourage and maintain safe working conditions; but there remain some who, while paying lip service to the ideals, fall far short of them in practice. Until the standard of professional conduct of everybody working in coal mines rises to such a peak that deliberate evasion or lack of enthusiasm in enforcing safety principles is ostracized, no safety measures will be wholly effective. (By 'professional' is meant all classes, owners, managers, engineers, officials and workmen.) The only alternative to this voluntary change of attitude is a coercive policy as exemplified by 'thousands of regulations' or 'hordes of inspectors', a policy that the vast majority of mining men regard with despair.

The science and art of mining is in a state of constant change; quite literally, nothing is ever static in a mine, and it is to be hoped that the Mines Department, when framing the new Coal Mines Bill which will be drafted as the result of the Commission's deliberations, will pay due consideration to the recommendation that the Bill itself should be concerned with principles only, details being dealt with by orders and regulations which can be amended from time to time without having recourse to Parliament to meet the changing conditions in mines.

After a general introduction, the report gives a historical summary of the development of safety legislation in mines and traces briefly the origin and subsequent history of the mines inspectorate of Great Britain. It then goes on to discuss in detail various phases of mining organization, methods of working and ancillary operations as well as problems concerned with the preservation of health and the prevention of industrial diseases.

It is proposed that both the administrative staff at the Mines Department and the inspectorate should be strengthened and reorganized with a view of giving the Department and the inspectors a bigger sphere of activities, greater authority, wider powers and better opportunities of keeping in touch with the research stations. It is hoped 
that the senior inspectors will then be able to keep in closer personal touch with the mines in their districts and that, because of their opportunities of gaining wide experience of various mining problems, they may come to be regarded even more in an advisory capacity than has in fact been the custom heretofore. The chances of promotion and suggested general all-round increase in salary, combined with appointment by selection after interview instead of by written examination, ought to attract more experienced and better trained recruits into the ranks of the inspectorate. In the past, many men who wanted to become inspectors of mines, and if selected would have made good inspectors, have been afraid to enter into open competition against younger men owing to the time that has elapsed since they studied the fundamental sciences.

At the present time, the Mines Department, through the Board for Mining Examinations, controls the examinations for the certificates of competency that have to be held by colliery managers and under-managers in Great Britain. The Board was subjected to two kinds of criticism from witnesses, $(a)$ against its present constitution, and (b) against the character of the examinations. It was pointed out that there is no system of rotational retirement and that no representative of any education authority or class of official other than the mine manager has a seat on the Board. The complaint about the character of the examinations was that they may allow candidates to pass without showing any real evidence of adequate scientific training. The Commissioners recommend the extension of statutory certificates to several other classes of officials besides managers, undermanagers and surveyors and, as a consequence, propose that the present Board be reorganized into a central controlling board of seven members who shall retire in rotation. They further recommend that the Board might accept as fulfilling part of their requirements the examinations held by various technical societies or institutions. They also suggest that the new board should investigate the principle of compulsory attendance, by every candidate, at his local technical school or other institute. The Commission's second recommendation at present applies particularly to institutions which cater for officials junior to the colliery manager. The institutions concerned with other branches of engineering have their own professional examinations, but the Institution of Mining Engineers has so far held back.

The Commissioners have examined the whole question of mining research and suggest that a central research organization under the control of the Secretary for Mines ought to be an integral part of the Mines Department, with arrangements for interchange and close co-operation between its staff, the staff of the Department's Testing Station and the inspectorate; at the present time, research in the mining industry is mainly financed by grants from the Safety in Mines Research Board, though a separate organization is maintained by the British Colliery Owners' Research Association, and numerous items of local interest are investigated by individual mining engineers and institutes.

The value of research is realized by the mining industry, but the results are not so well co-ordinated as they might be and take a long time to reach the individual colliery manager. Another point emphasized is that the majority of mining research work can be divided into two complementary sections, namely, that carried out in the laboratory and that in the mine respectively. The Commission is aware that a vast amount of possibly valuable information obtained in the laboratory at the research stations has not been translated into practice, and thinks that the Mines Department, through its research organizations, should be responsible for making arrangements for testing out in practice the results obtained in the laboratories. In this respect the close co-operation of the inspectorate would be invaluable.

Another matter of general interest in the report is health, and in particular silicosis, the incidence of which has greatly increased in recent years in portions of the South Wales coalfield. The Commissioners have recommended the use of definite and well-tried palliatives but, in view of the widespread, in fact international, interest that is being taken in the question, have not been too rigid in their conclusions. They are further agreed in recommending strongly that the Mines Department should employ a sufficient staff to ensure that the problem is pursued with the utmost vigour.

The Commissioners also recommend that a permanent 'General Staff' should be formed at the Mines Department with an advisory committee representative of all interests concerned to stimulate local safety propaganda, to collect, digest and circulate to similar voluntary organizations in each coalfield, material and ideas for a continuous safety campaign. They add that the principle of medical examination and certificates of fitness before employment should be applied to all young persons, and the minimum age of entry into a mine should be raised from fourteen to fifteen years. They also direct attention to the need of systematic training for all new entrants into the mining industry.

In the Commissioners' opinion, the amalgamation of mines into large and singly-owned groups renders necessary a redistribution of the statutory responsibilities of owners and managing officials, 
so that the responsibility for safe working shall be fixed on those who have the effective powers of control and not solely, as at present, on the technical employees. Among the many technical recommendations relating to mining practice are important proposals for laying down and maintaining more definite standards of ventilation, for improving and intensifying the system of supporting the underground workings and securing the general application of the principles of roof control, which have been the subject of much recent research work, for improving the physical and material conditions under which haulage opera- tions are conducted below ground, and for strengthening the precautions in connexion with explosives, electricity, shot-firing and coal dust.

In conclusion, while doubtless many of the recommendations of the Commissioners will be hotly debated when the new Bill is passing through the House of Commons, its most bitter opponent must acknowledge that the Commissioners have carried out their difficult task with moderation and vision. They have attempted to be helpful to everybody engaged in the production of coal, and appear to have held the scales of equity admirably.
J. A. S. Ritson.

\section{Liquid Helium}

By Dr. J. F. Allen, Royal Society Mond Laboratory, and Dr. H. Jones, Imperial College, London

$\mathrm{T}$ HE properties of liquid helium can best be considered under two headings: (a) properties in thermal equilibrium, $(b)$ transport effects. The equilibrium properties, which have been the subject of many careful investigations in Leyden and elsewhere, may be regarded as fairly well established. These include the determination of the specific heat for different temperatures, the variation of density with temperature at different constant pressures, and the relation of the saturated vapour pressure to the absolute temperature scale. The investigations of transport effects such as the flow of the liquid through tubes, heat conductivity and associated effects are still in an early stage of development, and no clear understanding of these phenomena has yet been reached. The subject was discussed at a meeting following the International Refrigeration Congress in July and also during the Cambridge meeting of the British Association. In this article we shall confine our attention largely to the interesting newly discovered transport effects, and give an account of recent experiments the results of which at present seem to find general acceptance.

\section{Equilibrium Properties of Liquid Helium}

Helium at atmospheric pressure liquefies at $4.22^{\circ} \mathrm{K}$.; the critical temperature is $5.2^{\circ} \mathrm{K}$. Generally speaking, the temperature range over which the properties of liquid helium have been measured extends only down to $1^{\circ} \mathrm{K}$., since this is the lowest temperature conveniently reached by lowering the vapour pressure over the surface of the liquid. At $2 \cdot 19^{\circ} \mathrm{K}$. under its own vapour pressure, liquid helium undergoes a remarkable transformation. As the liquid is cooled through $2 \cdot 19^{\circ} \mathrm{K}$., the specific heat jumps suddenly from a value of 0.4 cal. per gm. per degree to more than 5 cal. per gm. per degree, thereafter falling rapidly, approximately as $T^{5}$. Simon has recently shown that at very low temperatures $\left(0.02^{\circ}-0.05^{\circ} \mathrm{K}\right.$.) produced by adiabatic demagnetization of iron ammonium alum, the specific heat of liquid helium varies as $T^{3}$.

The transformation at $2 \cdot 19^{\circ} \mathrm{K}$. has also a remarkable effect on the expansion coefficient of liquid helium. Above that temperature it is positive, while below it is negative, although there is no discontinuity in the value of the density itself at $2 \cdot 19^{\circ} \mathrm{K}$.

Phase transformations of the type that liquid helium undergoes at $2 \cdot 19^{\circ} \mathrm{K}$. are known in other branches of physics; for example, the Curiepoint transformation of a ferromagnetic, the orderdisorder transformation of certain alloys, and the transition between the superconductive and the normal state of a metal. The temperature of the transformation in liquid helium is known as the $\lambda$-point, a name introduced by Ehrenfest. The modification of the liquid below the $\lambda$-point is generally referred to as helium II, that above the $\lambda$-point as helium $\mathrm{I}$.

Liquid helium at $1^{\circ} \mathrm{K}$. can be solidified under an external pressure of 25 atmospheres. At higher temperatures, greater pressures are required to produce the solid. The properties of liquid helium I are such as would be expected of an ordinary liquid of very low boiling point. It is far otherwise with liquid helium II. In the first place, it is an 